\title{
Chest pain in an adolescent male
}

\author{
Anjali Bhagra $\cdot$ Smitha Suravaram • Jana L. Anderson
}

Received: 26 December 2007 / Accepted: 30 June 2008 / Published online: 3 September 2008

(C) Springer-Verlag London Ltd 2008

A 15-year-old boy was referred to our emergency department for evaluation of subcutaneous emphysema. The patient had presented with gradual onset of dull resting chest pain lasting for almost an hour. The nature of the pain subsequently changed to sharp and radiated to his throat. $\mathrm{He}$ had undergone a chest X-ray at the outside emergency department which was remarkable for subcutaneous emphysema. Laboratory evaluation revealed no abnormality. He was subsequently transferred to our emergency department without any further intervention. The patient was symptom

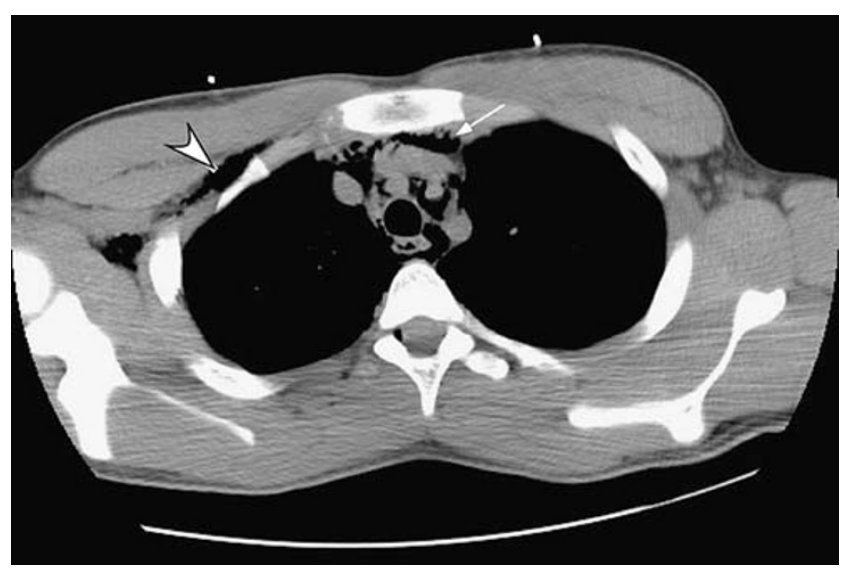

Fig. 1 CT confirming subcutaneous emphysema (arrowhead) and extensive pneumomediastinum (arrow)

\footnotetext{
A. Bhagra

Department of Internal Medicine, Mayo Clinic College of Medicine, Rochester, MN, USA

S. Suravaram $(\varangle) \cdot J$. L. Anderson Department of Emergency Medicine, Mayo Clinic College of Medicine,

Generose G-410, 200 First Street SW, Rochester, MN, USA

e-mail: suravaram.smitha@mayo.edu
}

free upon arrival. He denied any history of trauma or prior such episodes. Physical examination revealed a well appearing male, alert, oriented, and in no acute distress with palpable subcutaneous emphysema over the right trapezius muscle and neck. A computed tomography (CT) scan of the chest was obtained (Figs. 1 and 2). Chest CT confirmed the presence of subcutaneous emphysema as seen in Fig. 1 (arrowhead). There was additional evidence of extensive pneumomediastinum (white arrow). There was no pneumothorax, obvious esophageal or tracheolaryngeal perforation, or fistula.

Spontaneous mediastinal emphysema (Hamman's syndrome/pneumomediastinum) is a rare condition which is usually benign and nonrecurrent. It is known to be

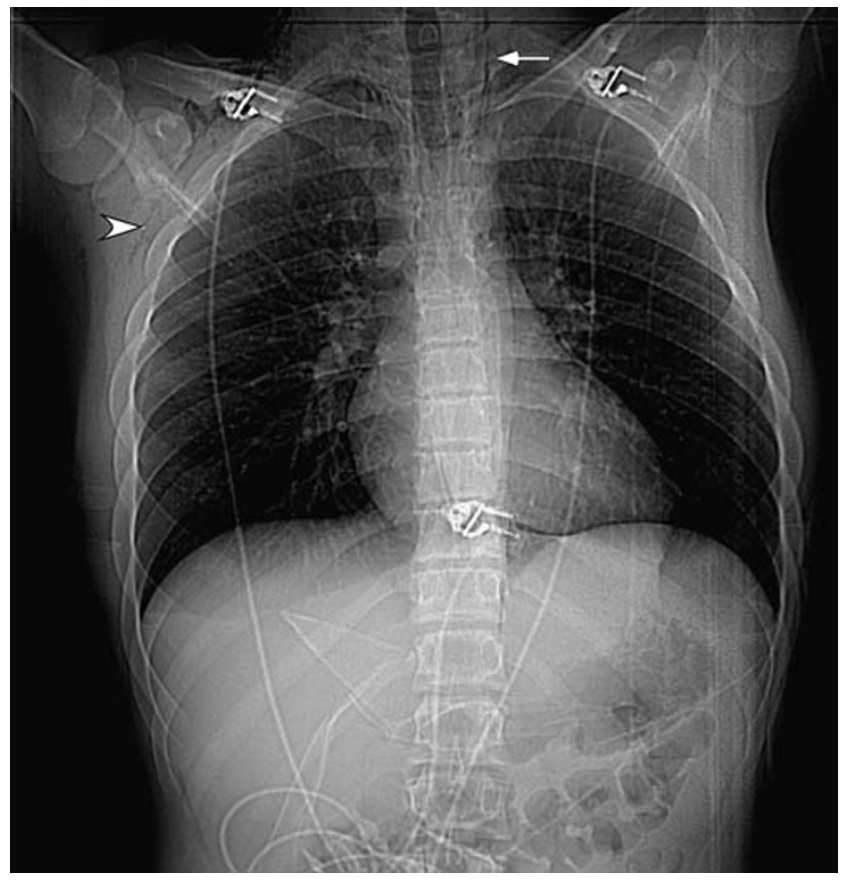

Fig. 2 Scout view depicting lucency along left mediastinal border (arrow) associated with pneumomediastinum. Also note the subcutaneous emphysema in the right chest wall (arrowhead) 
associated with transiently elevated intra-alveolar pressures [1]. It may present without any underlying precipitating factors or may be secondary to many factors [1]. The commonest presentation is with chest pain and dyspnea, with subcutaneous emphysema being the most common sign [1]. A precordial crunching sound synchronous with the heartbeat is the characteristic Hamman's sign [1], which was absent in our patient. Treatment is expectant [1]. The patient was observed for a few hours and subsequently dismissed. The patient did well on follow-up and had an uneventful course.

Conflicts of interest None.

\section{Reference}

1. Newcomb AE, Clarke CP (2005) Spontaneous pneumomediastinum: a benign curiosity or a significant problem? Chest 128(5):3298-3302 